pausal pill to control dysfunctional bleeding and hot flushes. If this was an accepted prophylactic many women would avoid hysterectomy for dysfunctional bleeding. Then after the age of 52 the postmenopausal pill containing even less oestrogen would, could, and maybe should be taken for many years to reduce the chances of myocardial infarction and osteoporosis. All this is I suppose contingent on women giving up smoking cigarettes.

New Cross Hospital,

Wolverhampton WV10 OQP

Alan M S Sith

SIR, - I would like to comment on two aspects of the leading article by Dr J C Stevenson and Dr M I Whitehead (28 August, p 585). They strongly advocate the use of long-term oestrogen preventive treatment and accuse doctors of managing the condition "too conservatively." It is important to try to balance the risks against the benefits of treatment.

Benefits although real may not be so great as is claimed. We have at present only three patients out of a practice population of 8300 suffering from disabling clinical osteoporosis: two secondary to rheumatoid arthritis and one to prolonged treatment with corticosteroids. Limb fractures are much commoner, and perhaps half of these could be prevented by oestrogens.

Against these benefits must be set the possible complications of treatment. I do not agree that "The risks of oestrogen treatment have been overstated." A multicentre longterm surveillance of mortality and cancer incidence is in progress under Professor Vessey of the department of community medicine and general practice, Oxford. Most family doctors would prefer to await the conclusions of this research before exposing their patients to unknown risks.

Calcium supplements offer an alternative form of treatment which is probably safe and certainly cheaper. Two studies have shown that calcium is at least partly effective in the treatment of osteoporosis. One of the references quoted by $\mathrm{Dr}$ Stevenson and Dr Whitehead ${ }^{1}$ in fact showed that calcium was intermediate in effect between oestrogen and placebo. A further study supports this view. ${ }^{2}$

Bollington,

JeAN CoOpe

Near Macclesfield SK10 5JL

${ }^{1}$ Horsmann A, Gallagher JC, Simpson $M$, Nordin

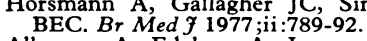

Albanese A, Edelson A, Lorenze E, Woodhall M, Wein E. NY State $\mathcal{F}$ Med $1975 ; 75: 326-36$.

SIR,- - Two of the recently suggested aetiological factors and possible agents for treatment of osteoporosis not mentioned in the article by Dr J C Stevenson and Dr M I Whitehead (28 August, p 585) are copper and vitamin $\mathrm{K}$.

The link between copper and osteoporosis has been suggested by animal and human data. Copper deficiency in animals has been shown to lead to increased absorption of bone and histological changes similar to those found in patients with osteoporosis. ${ }^{1}$ Similarly, bone changes have been noted in infants with copper deficiency, and these revert to normal on copper replacement. ${ }^{2}$ Although no study so far has looked at copper in patients with postmenopausal osteoporosis, it has been suggested that such a link should be investigated. ${ }^{3}$

The importance of vitamin $\mathrm{K}$ in osteoporosis is suggested by the fact that vitamin $\mathrm{K}$ is an essential cofactor for the microsomal enzyme carboxylase, which converts glutamic acid to $\gamma$-carboxyglutamic acid, ${ }^{4}$ which is present in the matrix of the bone. ${ }^{5}$ The $\gamma$ carboxyglutamic-acid-containing protein in the bone, osteocalcin, ${ }^{6}$ has calcium-binding sites. ${ }^{7}$ In vitamin $\mathrm{K}$ deficiency it has been shown that glutamic acid is not carboxylated and the non-carboxylated sites exhibit very weak reaction with calcium ions. ${ }^{7}$ The facts which support its use in osteoporosis are: (1) vitamin $\mathrm{K}$ reduces calcium excretion in patients with osteoporosis ${ }^{8}$; (2) increase in osteocalcin results in increase in bone density ${ }^{9}$; (3) osteoporosis of old age or that associated with steroid treatment exhibits increased urinary $\gamma$-carboxyglutamic acid, which reflects increased breakdown of osteocalcin, the vitamin-K-dependent protein. ${ }^{10}$

G S RAI Whittington Hospital,
London N19 $5 \mathrm{JG}$

'Baxter JH, Van Wyk JJ, Follis RH. Bull Johns Hopkins Hosp 1953;93:25-31

Ashkenazi A Levin S, Dialdetti M, Fishel E, Benvenisti D. Paediatrics 1973:52.524-33

Golden MHN. In: Exton-Smith AN, Caird FI, eds. Metabolic and nutritional disorders in the elderly. Bristol: John Wright, 1980:45-57.

' Larsen AE, Suttie JW. Proc Natl Acad Sci 1978; 75:5413-6.

5 Stenflo J. J Biol Chem 1973;248:6325-32. Trends in
' Houschka PV, Lian JB, Gallop PM. Trends Biochem Sci 1978; 3:75-8.

'Stenflo J. F Biol Chem 1972;247:8167-75.

8 Tomita A. Clin Endocrinol 1971;19:731-6.

Lian JB, Reit B, Roufosse AM, Glimcher MJ, Gallop PM. In: Suttie JW, ed. Vitamin $K$ metabolism and vitamin $K$ dependent proteins. Baltimore: University Park Press, 1970:237-44. Gallop PM, Lian JB, Houschka PV. N Engl f Med
1981;306:1460-6.

\section{Hypertension: comparison of drug and non-drug treatments}

SIR,-The meta-analytic review of hypertensive treatments by Dr Gavin Andrews and others (22 May, p 1523) is informative and necessary for the promulgation of effective non-pharmacological treatment of hypertension. It should, however, be noted that by differentiating treatment modality and effect size much information regarding the potential interactive effects of combined regimens is lost. Thus, the interpretation of Andrew's meta-analysis is limited in scope. It fails to consider the many instances where combining treatment techniques is both desirable and effective. Even in the case of drug treatment, the use of various non-pharmacological adjunctive techniques often potentiates the lowering of blood pressure. Furthermore, the effects of combined non-pharmacological treatment become even more important in light of typical compliance to drug therapythat is, about $50 \% .^{1}$

The fact that Andrews et al support the use of non-pharmacological interventions for hypertensive patients is highly commended. Yet the approach physicians should take in treating mildly hypertensive patients is not answered solely by the analysis of individual treatment effectiveness. Efficacy of any kind of therapy is regulated by a number of factors above and beyond the specific technique. Therefore, the advocation of a single regimen to decrease blood pressure in all patients is unwarranted. Whether or not weight reduction, yoga, muscle relaxation, exercise training, biofeedback, salt restriction, or a combination thereof is most effective depends in part on the individual as well as the practitioner. Factors such as patient expectation, level of compliance, motivation, etc, comprise important variables which are considered all too infrequently. ${ }^{2}$ Therefore, individuation of treatment to the patient is advocated. This would include the integration of various treatment packages with individual patient characteristics. Of course, such a procedure requires more time, but improved effectiveness is the pay off. Whether this question of cost effectiveness is worth while is undoubtedly left up to the individual physician. After all, the treatment of choice must be integrated with his or her personality as well.

Evidence supporting the individuation of treatment in areas outside hypertension, along with the authors' firm conviction that treatment is enhanced through the consideration of personality variables ${ }^{3-5}$ (both of the patient and the physician), provided the impetus for this letter.

JOHN SOMMERS D BALFOUR JEFFREY

Department of Psychology, Missoula of Montana,

USA

${ }^{1}$ Foster SB, Kousch D. Nursing Clinics of North America $1981 ; 16: 331$

( Baltimore: Johns Frank J. American fournal of Psychotherapy 1971; 25:350-6

Prupp HH. Psychotherapy: Practice 1978;15:359-60.

Do alcoholics recover?

SIR,-As Dr W H (7 August, p 443) points out, surely the question is not "Do alcoholics recover ?" (3 July, p 3) but "How do (a considerable proportion of) alcoholics recover ?" Clearly alcoholics "Do not ... . inevitably slide downhill ... with few if any recovering"; but even nowadays (though less so than in the past) this utterly false stereotype still contributes to the lack of interest of doctors in the fate and management of alcoholics. Not surprisingly therefore many doctors may indeed "seldom meet recovered alcoholics," but those doctors (such as the members of the British Doctors' Group, referred to by $\operatorname{Dr} \mathrm{E} D$ McConnell (7 August, $p$ 443)) who assist problem drinkers and, of course, also the members of Alcoholics Anonymous all meet a great many recovered alcoholics. I have been privileged to observe the steady progress of quite a number of alcoholics treated in the Warlingham Park Unit in the $1950 \mathrm{~s}^{1-3}$ who have maintained their sobriety and with it a healthy, contented lifestyle (to the great benefit also of their families) for nearly three decades. Incidentally, the treatment results of these patients ${ }^{2}$ - onethird recovered, one-third improved, one-third unchanged-are very much in line with those various studies referred to in your leading article.

Undoubtedly some alcoholics recover without treatment or, as reported by Orford and Edwards, ${ }^{4}$ with the help of detailed, judicious, and informed advice-although these authors' finding that (mainly outpatient) treatment gave no better result than expert "advice" was obtained in a special group of alcoholics-that is, still living with their wives. Whether such results also apply to prognostically less 
favourable groups of alcoholics (such as single, divorced, or widowed men and women) is as yet unknown but may appear doubtful to the practising clinician. ${ }^{3}$ The statement that, "Treatment may actually make some alcoholics worse" by protecting them from the consequences of their drinking or by fostering inactivity surely applies only to utterly inadequate "treatment." The risks arising from the behaviour of well-meaning "enablers" who shelter the alcoholic from experiencing the painful effects of his drinking on himself (and others) and the importance of fostering the patient's responsibility for his recovery, his own initiative, and active participation in the therapeutic programme are surely nowadays well known to every experienced therapist. The finding of some community-based studies that sociopathy did not predict outcome is surprising; it contrasts with most clinicians' observations $^{1-3}$ and also with the statement in your leading article that "the best predictor is stability in one's own job and marriage." Social stability (with its link with "good outcome") is hardly a characteristic feature of sociopathy.

M M Glatt

University College Hospital

Alcoholism Teaching Centre,

St Pancras Hospital

1 Glatt MM. Br F Addict 1955;52:55-92.

2 Glatt MM. Lancet 1959;ii:397-8.

3 Glatt MM. Alcoholism. London: Teach Yourself Books, 1982.

Orford J, Edwards G. Alcoholism. London: Oxford University Press, 1977.

\section{Benoxaprofen}

SIR,-In analysing the suspension of the product licence of a drug linked to at least 61 deaths and 3500 adverse reactions in the past two years, the author of your leading article (14 August, p 459) has raised serious but necessary questions about the roles of the manufacturer, pharmaceutical companies in general, the Committee on Safety of Medicines, the lay press, practising doctors, and even the public at large. No mention was made, however, of the role of editors and advertising managers of medical journals, under whose aegis Opren (benoxaprofen) was provided with a credible context from the outset.

The influence of pharmaceutical advertising directed at prescribing doctors-and the responsibility of those persons at medical journals who approve an advertisement for publication-must also be considered. In this instance, two-page and three-page advertisements for benoxaprofen appeared prominently in no fewer than 20 issues of the $B M F$ alone in the two years since the introduction of the drug. One such advertisement favourably compared the five-letter brand-name product with the more unwieldy generic name counterparts: diclofenac, flurbiprofen, indomethacin, and piroxicam. As in many pharmaceutical advertisements, the prescribing information was obscurely placed, and included vague sentences such as "Peptic ulceration has occured (sic) only rarely."

Practising doctors and medical editors alike may resent the implication that frequency and prominence of advertisements for a drug increase the number of prescriptions. I believe most doctors would say they pay little attention to the advertisements, much less prescribe a drug on the basis of one. None the less, the irony is inescapable that while manuscripts, including those dealing with clinical drug trials and post-marketing surveillance programmes, often undergo extensive revision before acceptance for publication, paid advertisements extolling only the virtues of various products generally are accepted without modification.

In the face of the need to maintain fiscal viability while upholding the highest editorial standards, what is a medical journal to do in regard to advertising ? The issue needs to be explored by both editors and medical associations at their meetings. One proposal has been raised $^{1}$ and seconded" for a "physician boycott" of drugs that are unethically promoted. Alternatively, I would propose that medical journals reject advertising for prescription products that are also promoted and advertised in the lay press. In addition, as a way of discouraging the rush to prescribe new drugs, I would propose that journals either wait for a period of time after the introduction of a drug before accepting an advertisement for it, or confine the content of the advertisements to prescribing information.

In my opinion, the benoxaprofen affair points out the need for more careful "peer review" by medical editors and other doctors of pharmaceutical advertisements submitted for publication.

Medical Journal of Australia,

Alan BLUM

Glebe

New South Wales,

Australia 2037 ${ }^{1}$ Solomon SD, Grimmett BL, Maurer KH, Levin NW.
$N$ Engl $\mathcal{F}$ Med $1979 ; 300: 203$.
${ }^{2}$ Mallace AH. N Engl f Med 1979;300:734.

${ }^{*}{ }^{*}$ The $B M \mathcal{F}$ has a code which it applies to all advertisements; the prime requirement is that: "Statements of fact should be supported by trustworthy evidence." We do reject advertisements or ask the advertiser to modify the wording or presentation on grounds of accuracy or taste. For us to object to an advertisement on the grounds of frequency would, however, be unduly quixotic.-ED, $B M 7$.

SIR,-While we generally agree with the thoughtful leading article on benoxaprofen (14 August, p 459), there is one correction which is germane to your query as to whether the Committee on Safety of Medicines acted too slowly in banning the drug.

In a letter to the $B M 7$ ( 29 May, p 1630) Lilly vice-president Ian Shedden stated that "no jaundice" had been seen "in approximately 2200 carefully followed patients who participated in clinical trials in the USA." This statement is repeated in the leading article. In fact five cases of reversible jaundice, including four cases with concomitant (also reversible) renal disease, occurred in patients in US clinical trials prior to the US marketing of benoxaprofen in May 1982. ${ }^{1}$ The first case occurred in 1978

Although the US cases occurred in younger patients, they bear a striking similarity to many of the fatal cases reported in the UK. Until we know whether Lilly informed the Committee on Safety of Medicines promptly about these cases, we cannot determine whether the Committee on Safety of Medicines acted too slowly in banning benoxaprofen.

The best mechanism for early warning of side effects, especially those occurring more frequently than once in a thousand patients, is the carefully controlled and monitored clinical trial. Unless there is prompt reporting of the results of such trials by the sponsoring drug company to all governmental agencies in countries marketing or planning to market a particular drug, the Committee on Safety of Medicines, the Food and Drug Administration, and similar agencies in other countries will not be acting on the best available information.

SIDNEY M WOLFE

EvE BARGMANN

Health Research Group,
Washington DC 20036

' July 2, 1982. Submission by Lilly to the Food and Drug Administration.

\section{Prescription-event monitoring}

${ }^{*}{ }^{*}$ The following is a draft of a letter to be sent to all GPs in England.-ED, $B M F$.

SIR,-In my letter of 26 February this year I described the preliminary results of our pilot study of prescription-event monitoring. Your response was excellent and I felt that the rapid feedback, less than one month after the "green forms" had been distributed, would be appreciated. Although this was only a smallscale study designed to test the system, some interesting and fairly reassuring data on the two drugs-fenbufen (Lederfen) and benoxaprofen (Opren)-were also obtained.

Among approximately 6000 green forms returned for benoxaprofen, there were eight in which jaundice had been reported as an "event." Further inquiries eliminated some patients with alternative causes and others who were not taking the drug, and there remained only three cases in which benoxaprofen was a possible cause. Prescription-event monitoring had thus signalled a potential risk, but I considered that these few reports did not justify raising an alarm, at least until the hypothesis had been tested in a larger series.

Four months later, a small cluster of reports of benoxaprofen-associated jaundice appeared in the journals. They tended to strengthen our earlier signal, and defined the problem as one which mainly affected elderly patients. The manufacturers circulated a warning to prescribers on 21 June recommending that elderly patients should take no more than $300 \mathrm{mg}$ daily. On 3 August, it was announced that the licence for benoxaprofen had been temporarily suspended by the Department of Health and Social Security.

The following preliminary statistics from the pilot study may be of interest:

(1) Ninety-five per cent of benoxaprofen and $96 \%$ of fenbufen patients had been prescribed daily doses of $600 \mathrm{mg}$ or more.

(2) Fifty-six per cent of both groups had been treated for osteoarthritis. Twenty per cent of the benoxaprofen and $11 \%$ of the fenbufen group had been treated for rheumatoid arthritis.

(3) Thirty-six per cent of the benoxaprofen group were under 60 years of age, $29 \%$ were aged $60-69$, and $35 \%$ were over 70 . Corresponding figures for fenbufen were $33 \%, 25 \%$, and $42 \%$ respectively.

(4) About $40 \%$ of patients on benoxaprofen and $43 \%$ of those on fenbufen continued their treatment beyond the 12 months of the study. Of the remainder, the mean duration of treatment was approximately 18 weeks for benoxaprofen and 15 weeks for fenbufen.

(5) In both groups the overall mortality during the 12 months of the study was $3 \%$.

Excepting that relatively fewer patients with rheumatoid arthritis were treated with fenbufen, the two groups were very similar in other respects. Although the questionnaires were not designed to test efficacy, a number of doctors volunteered the information that patients taking benoxaprofen 